\title{
Improving Surface Roughness of Burnished Components using Abrasive Particles
}

\author{
Pavana Kumara $^{1 *}$ and G. K. Purohit ${ }^{2}$ \\ ${ }^{1}$ Faculty of Mechanical Engineering, SMVITM Udupi-574115, Karnataka, India \\ ${ }^{2}$ Department of Mechanical Engineering, PDACE Kalaburagi-585102, Karnataka, India \\ *Email: pavan.mech@sode-edu.in \\ Phone: +91 9449700900; Fax: +91 8202589184
}

\begin{abstract}
Roller burnishing process was carried out on free cutting brass materials in the presence of fine silicon carbide abrasives in the form of paste on a pre-machined surface. The results of 'without-paste' burnishing (plain burnishing, PB) and 'with-paste' burnishing (abrasive assisted burnishing, $\mathrm{AAB}$ ) processes are compared to examine the effect of abrasive particles in the burnishing process. A $2^{4}$ full factorial design is adopted to develop the mathematical model for surface roughness regarding four process parameters like burnishing force, burnishing speed, burnishing feed and number of passes for both the cases, i.e. PB and AAB. Analysis of variance (ANOVA) was carried out to find the effect of process parameters and to check the adequacy of the models. The results show that the parameters have a significant effect on the response in PB to improve the surface roughness by $75 \%$ than the turned components. Whereas in AAB, fine abrasive particles as a single entity controlling the response and making other parameter effects as non-significant. Surface roughness further improved by $15 \%$ in $\mathrm{AAB}$ process.
\end{abstract}

Keywords: Roller burnishing; turning; abrasive paste; factorial design; surface roughness.

\section{INTRODUCTION}

Burnishing is essentially cold working, chip-less finishing process carried out using a hard and soft ball or roller on machined components. The irregularities present in premachined surfaces will be deformed due to the action of the ball or roller into valleys and causes plastic deformation. When peaks fill in the valleys, during this action of the burnishing tool, the properties at the surface like surface finish, microhardness, wear resistance, fatigue strength, corrosion resistance increases. Burnishing is chip-less when compared with the conventionally used chip removal, finishing processes Viz., grinding, lapping, honing [1]. This process can be carried out on the same machine tool as lathe where turning tool and burnishing tool can be fixed at same tool post. So, the time required to set the tool, change the tool, etc. decreases. The schematics of the burnishing process is shown in Figure1. The graphical representation of the burnishing process shows the formation of three different zones during the process and also represents the formation of compressive stresses at the surface at the end of the burnishing action. 


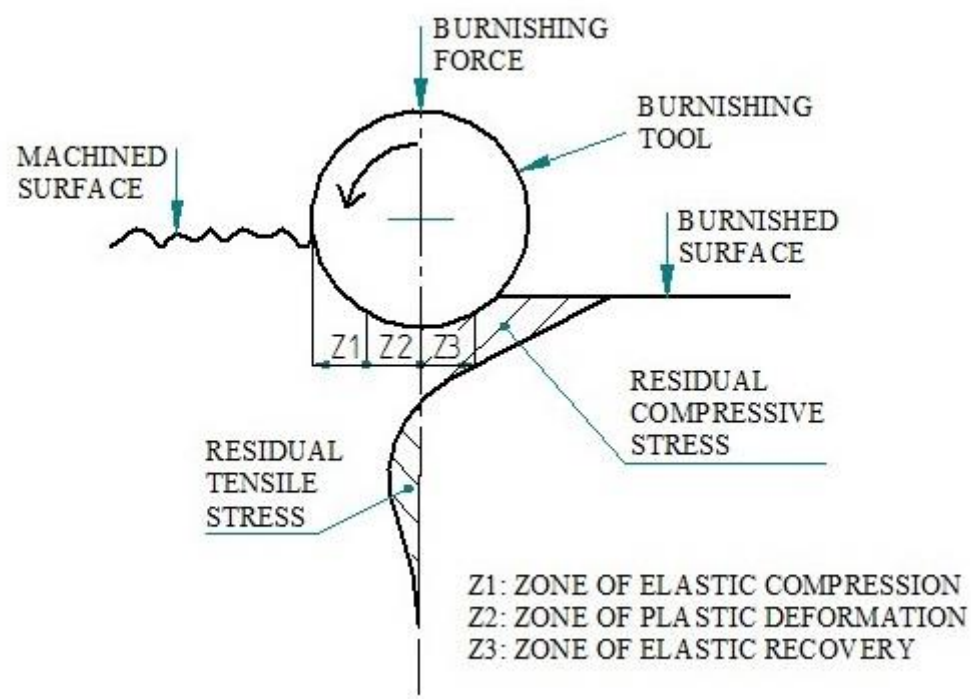

Figure 1. Schematics representation of roller burnishing process.

The effect of various ball burnishing process parameters such as speed, force, feed, number of passes and ball diameter on characteristics of the surface were studied on aluminium and brass workpieces. It was reported that all the parameters had a significant effect to improve the surface roughness to $0.1 \mu \mathrm{m}$ and microhardness by $60 \%$ [2]. The study carried out to find the influence of initial conditions of the workpieces and lubricants shows that higher initial surface roughness and hardness increases the final surface roughness of the ball burnished workpieces. The use of lubricants decreases surface roughness and microhardness at the surface, but the viscosity of the lubricant has no significant effect on characteristics [3].

The diamond-tip ball burnishing tool is recommended [4] to deform the $\mathrm{Rb} 40$ steel workpieces with $150 \mathrm{~N}$ force at two number of passes to get better surface roughness and three number of passes for better microhardness. It was observed that $60 \%$ improvement could be achieved in hardness of high strength low alloy (HSLA) steel by using ball burnishing process [5]. The effect of different orientation of the tool was studied [6] and concluded that the parallel burnishing orientation is better than cross-burnishing orientation in reducing friction coefficient. During ball burnishing process, surface finish was improved by $75 \%$, the friction coefficient reduced by $48 \%$ and weight loss by $60 \%-80 \%$.

Ball burnishing carried out on polyoxymethylene (POM), and polyurethane (PUR) polymers resulted in a decrease of surface roughness by $45 \%$ and $42 \%$ respectively. The coefficient of friction was reduced by $32.9 \%$ for POM polymers and $28.8 \%$ for PUR polymers and also wear rates decreased by $38.6 \%$ and $37.9 \%$ for POM and PUR polymers respectively [7]. Internal ball burnishing conducted on aluminium 2014 alloy resulted in significant improvement in microhardness and out-ofroundness [8].

Shot peened workpieces are applied to the burnishing process to improve their surface roughness and hardness further in aluminium and brass components, proving to burnish as a better treatment process [9]. The effect of both ball and roller burnishing process in all similar conditions in aluminium and brass workpieces was investigated, and it was interesting to note that ball burnishing process gives better results for both surface finish and surface hardness than roller burnishing, although the force sets at a 
higher level during roller burnishing [10]. The non-ferrous materials are tested with a roller burnishing process [11] and concluded that there was a considerable improvement in surface roughness and surface hardness. Surface quality and tribological studies were done on Aluminium-6061 [12] to investigate the effect of parameters along with the orientation of the tool. The surface finish improves by $75 \%$, the friction coefficient reduced by $48 \%$ and weight loss reduced by $60 \%-80 \%$.

Most recently published works show that the burnishing process can be used to reduce the coefficient of friction and to improve the drawing ratios of coated C60 steel [13] and in the medical field for improving corrosion resistance properties of the bio implantations [14]. Cryogenic burnishing is carried out to produce severe plastic deformation (SPD) layer on Ti-6Al-4V alloy to improve the surface integrity [15]. The ball burnishing process can significantly improve the corrosion resistance on the AISI 1045 steel along with enhancement of surface finish and hardness [16]. An attempt is also being made to enhance the wear resistance property of the titanium alloy using ball burnishing resulted in a $52 \%$ decrease in wear rate and $64 \%$ reduction in coefficient of friction [17]. The feed rate in turning process has a significant effect on surface roughness and power consumption. At higher feed rates the surface roughens increases affecting the quality of the components $[18,19]$. Authors have not found much work related to roller burnishing effect on surface roughness and microhardness in different conditions. In the current work, fine particles of silicon carbide abrasives were used in burnishing process to establish the relationship between the parameters and surface roughness.

\section{MATERIALS AND EQUIPMENT}

\section{Workpiece Material}

Experimental works were carried out on the free cutting brass material based on IS 3192007 Gr.1 considering its engineering applications in industries and difficulties in heat treatment to improve its mechanical properties. The chemical composition of the workpiece is given in Table 1. The raw material was received in the form of the rod in wrought condition from a local supplier with an initial diameter of $20 \mathrm{~mm}$ and 1 meter length. The rod was first cut to $0.25 \mathrm{~m}$ length from the initial length, and further, it is divided into nine parts of each part length $25 \mathrm{~mm}$ as a sampling length by making a small grove. A sample was kept as a reference for the turning process and the remaining eight samples were subjected to the burnishing process.

Table 1. Chemical composition of free cutting brass.

\begin{tabular}{cccccccc}
\hline Element & $\mathrm{Zn}$ & $\mathrm{Pb}$ & $\mathrm{Fe}$ & $\mathrm{Sn}$ & $\mathrm{Mn}$ & $\mathrm{P}$ & $\mathrm{Cu}$ \\
\hline wt.\% & 39.77 & 3.60 & 0.414 & 0.381 & 0.0330 & 0.0062 & $\mathrm{Bal}$. \\
\hline
\end{tabular}

\section{Roller Burnishing Tool}

A custom designed and fabricated roller burnishing tool shown in Figure 2 was used on the conventional lathe for burnishing. A ball bearing is used as a roller, having an outer diameter of $26 \mathrm{~mm}$, the inner diameter of $10 \mathrm{~mm}$ and width of $8 \mathrm{~mm}$. The roller (10) can be replaced by removing the key (9). The lower body (1) supports all the inner parts. The locking plate (2) is used to hold the shaft in position. Spring holder (3) and 
nut (4) are provided to support the other end of the shaft. Spring (5) measures the deflection of the roller against the workpiece surface, thus helps in applying the required amount of force. Upper body (6) is provided with required threads to get assembled with the lower body. Roller holder $(7,8)$ shaft is an element that holds the roller, and it is inserted in the upper and lower body assembly by applying force. The stiffness of the spring used in the tool was $1.66 \mathrm{~N} / \mathrm{mm}$, and it is correlated with force during experimentation.
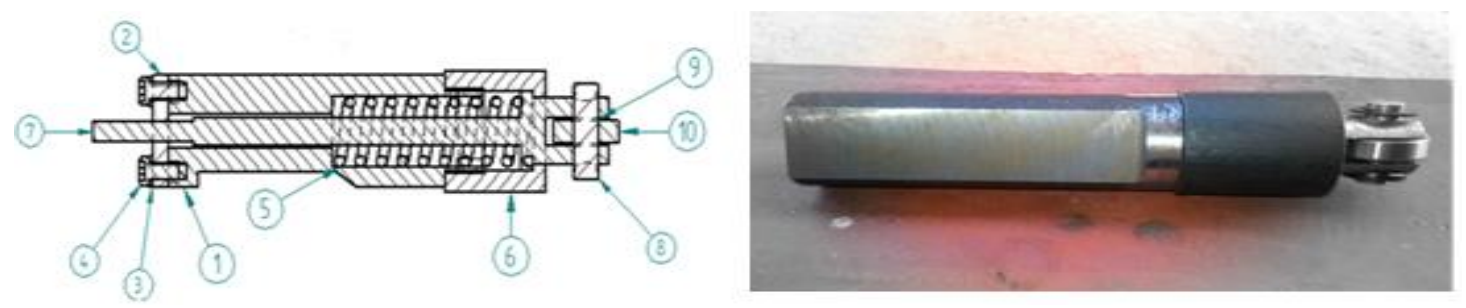

Figure 2. Roller burnishing tool parts (1. lower body, 2. locking plate, 3. spring washer 4. nut, 5. spring, 6. upper body, 7. roller holder with tool shaft, 8. roller shaft, 9. key, 10. roller).

\section{Experimental Work}

UNITECH MTT 636 all geared lathe is used to carry out the burnishing experiments. Experiments are designed according to the $2^{4}$ full factorial design. Turning is carried out to reduce the diameter of the workpieces from $20 \mathrm{~mm}$ to $17 \mathrm{~mm}$ in diameter initially. Once the turning was carried out, the abrasive paste (made: Carborondum Universal Limited) consisting of fine abrasives was applied over its length, and the experiments were conducted in $\mathrm{AAB}$ condition. The paste is applied manually over the surface by using non-stick cloth. During this experimentation, kerosene is applied as the lubricant to avoid excess heat generation. In a later stage, 16 experiments were conducted without using abrasive paste as a PB case under the same set of parameter levels. The surface roughness measured using Surftest, Mitutoyo SJ-210 roughness tester. Figure 3 shows the burnishing process operation. The initial surface roughness, Ra, of the turned workpieces was found to be in the range of 2.62-2.83 $\mu \mathrm{m}$.

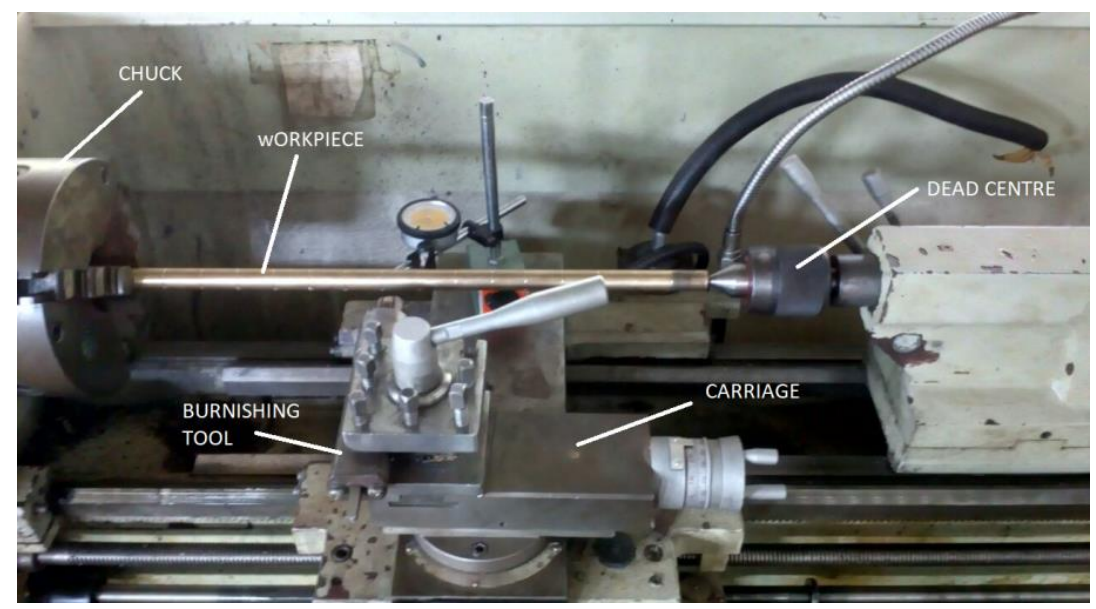

Figure 3. Burnishing operation in $\mathrm{AAB}$ case. 


\section{DESIGN OF EXPERIMENT}

Design of experiment proposed by the Box and Hunter [14] was used to design the experiments in current research. The method provides better flexibility in designing the experiments which reduce the time and economic factors of the experimentation. The conventional method of varying a single parameter at each experimental run can be overcame by this method. Four parameters at two levels are tested in 16 experimental runs systematically. Parameters level and design matrix for $2^{4}$ full factorial design are presented in Table 2 and 3 respectively. The experimental runs were designed, and analysis of the results are carried out using the Minitab 2017 software tool.

The $2^{4}$ full factorial design being simplest of all factorial design of experiments was used to optimise the parameters for higher surface roughness within the range of the parameter levels. The folded errors will be less due to many experimental runs. Besides defining the level of effect of individual and interaction parameters on the response the factorial design also describes the process in the form of the user-defined mathematical model with a minimum number of experiments. in Eq. (1).

The linear regression model to predict surface roughness, Ra, can be written as

$$
\begin{aligned}
& Y=\beta_{0}+\beta_{1} X_{1}+\beta_{2} X_{2}+\beta_{3} X_{3}+\beta_{4} X_{4}+\beta_{12} X_{1} X_{2}+\beta_{13} X_{1} X_{3}+\beta_{14} X_{1} X_{4} \\
& +\beta_{24} X_{2} X_{4}+\beta_{123} X_{1} X_{2} X_{3}+\beta_{124} X_{1} X_{2} X_{4}
\end{aligned}
$$

In Eq. (1), Y represents any response or effect, while $\beta_{1}, \beta_{2}, \beta_{3}, \beta_{12}, \beta_{123}$ represent the regression coefficient to be evaluated by running experiments. $X_{1}, X_{2}, X_{3}$ and $\mathrm{X}_{4}$ are main effects and represents force, speed, feed and number of passes respectively. ANOVA test was used to check the adequacy of the models. Regression coefficients to develop the mathematical model in Eq. (1) can be calculated by using the Eq. (2).

$\beta_{j}=\frac{\left(\sum_{i=1}^{N} X_{j} Y_{i}\right)}{N}, j=0,1,2 \ldots \ldots \ldots . . K$

where, $\mathrm{N}=$ Number of trials, $\mathrm{K}=$ number of column of the design matrix, $\mathrm{X}_{\mathrm{j}}=$ value of a factor or interaction in coded form, and $\mathrm{Y}_{\mathrm{i}}=$ average of the values of the output parameters. $\beta_{0}$ is given as the average of output parameters obtained in all the trials.

Table 2. Level of parameters and their coded form.

\begin{tabular}{lcc}
\hline Parameter/ level & -1 & +1 \\
\hline Force $(\mathrm{N}) / \mathrm{X} 1$ & 98 & 294 \\
Speed (rpm)/ X2 & 165 & 770 \\
Feed (mm/rev)/ X3 & 0.049 & 0.98 \\
Number of passes/ X4 & 1 & 3 \\
\hline
\end{tabular}

\section{RESULTS AND DISCUSSION}

The results of $\mathrm{PB}$ and $\mathrm{AAB}$ are presented in Table 3. The tabulated surface roughness values show that reduction in roughness level can be achieved with the workpieces 
burnished using all the treatment combinations as per design matrix. The surface average surface roughness of the initial (turned) workpiece was in the range of 2.62$2.83 \mu \mathrm{m}$, and it can be brought up to $0.283 \mu \mathrm{m}$. Interestingly in both the cases the optimised level of parameters to get lower surface roughness level were found to be similar. The optimised level of parameters are high force of $294 \mathrm{~N}$, high speed of 770 $\mathrm{rpm}$, low feed of $0.049 \mathrm{~mm} / \mathrm{rev}$, and a higher number of passes of 3 . This may be due to the presence of abrasive particles which are helping the tool to squeeze the peaks in valleys further in AAB process compared to PB process. In general, it was noticed that the application of abrasive paste is advantageous over PB process.

Table 3. A $2^{4}$ design matrix and results of surface roughness, Ra, for PB and AAB case.

\begin{tabular}{|c|c|c|c|c|c|c|c|c|c|c|}
\hline \multirow[t]{2}{*}{ Run } & \multicolumn{2}{|c|}{$\begin{array}{c}\text { Force, } \mathrm{X} 1 \\
\text { (N) }\end{array}$} & \multicolumn{2}{|c|}{$\begin{array}{c}\text { Speed, X2 } \\
\text { (rpm) }\end{array}$} & \multicolumn{2}{|c|}{$\begin{array}{l}\text { Feed, X3 } \\
(\mathrm{mm} / \mathrm{rev})\end{array}$} & \multicolumn{2}{|c|}{$\begin{array}{l}\text { Number of } \\
\text { passes, X4 }\end{array}$} & \multirow{2}{*}{$\begin{array}{l}\text { Ra for } \\
\text { PB } \\
(\mu \mathrm{m})\end{array}$} & \multirow{2}{*}{$\begin{array}{l}\text { Ra for } \\
\text { AAB } \\
(\mu \mathrm{m})\end{array}$} \\
\hline & Level & Value & Level & Value & Level & Value & Level & Value & & \\
\hline 1 & -1 & 98 & -1 & 165 & 1 & 0.098 & -1 & 1 & 1.285 & 0.928 \\
\hline 2 & -1 & 98 & -1 & 165 & -1 & 0.049 & -1 & 1 & 0.667 & 0.453 \\
\hline 3 & -1 & 98 & 1 & 770 & -1 & 0.049 & -1 & 1 & 0.754 & 0.707 \\
\hline 4 & 1 & 294 & 1 & 770 & 1 & 0.098 & -1 & 1 & 0.925 & 1.040 \\
\hline 5 & 1 & 294 & -1 & 165 & -1 & 0.049 & 1 & 3 & 0.754 & 0.296 \\
\hline 6 & -1 & 98 & 1 & 770 & 1 & 0.098 & -1 & 1 & 0.821 & 0.612 \\
\hline 7 & 1 & 294 & 1 & 770 & -1 & 0.049 & 1 & 3 & 0.331 & 0.283 \\
\hline 8 & -1 & 98 & -1 & 165 & -1 & 0.049 & 1 & 3 & 0.868 & 0.320 \\
\hline 9 & -1 & 98 & -1 & 165 & 1 & 0.098 & 1 & 3 & 0.797 & 0.334 \\
\hline 10 & 1 & 294 & -1 & 165 & 1 & 0.098 & 1 & 3 & 0.806 & 0.416 \\
\hline 11 & 1 & 294 & -1 & 165 & 1 & 0.098 & -1 & 1 & 0.847 & 0.496 \\
\hline 12 & -1 & 98 & 1 & 770 & 1 & 0.098 & 1 & 3 & 0.654 & 0.634 \\
\hline 13 & -1 & 98 & 1 & 770 & -1 & 0.049 & 1 & 3 & 0.995 & 0.407 \\
\hline 14 & 1 & 294 & 1 & 770 & 1 & 0.098 & 1 & 3 & 0.764 & 0.411 \\
\hline 15 & 1 & 294 & 1 & 770 & -1 & 0.049 & -1 & 1 & 0.757 & 0.419 \\
\hline 16 & 1 & 294 & -1 & 165 & -1 & 0.049 & -1 & 1 & 0.774 & 0.600 \\
\hline
\end{tabular}

\section{Mathematical Models}

One of the main objectives in the current study is to develop mathematical models for surface roughness for each case. The regression equation for surface roughness in $\mathrm{PB}$ is as in Eq. (3), while in AAB is as Eq. (4).

$$
\begin{aligned}
& \mathrm{Ra}=0.8-0.056 \mathrm{X}_{1}-0.0498 \mathrm{X}_{2}+0.0624 \mathrm{X}_{3}-0.0538 \mathrm{X}_{4}-0.000687 \mathrm{X}_{1} \mathrm{X}_{2} \\
& +0.0283 \mathrm{X}_{1} \mathrm{X}_{3}-0.0271 \mathrm{X}_{1} \mathrm{X}_{4}-0.0215 \mathrm{X}_{2} \mathrm{X}_{3}-0.0103 \mathrm{X}_{2} \mathrm{X}_{4}-0.0533 \mathrm{X}_{3} \mathrm{X}_{4} \\
& +0.081 \mathrm{X}_{1} \mathrm{X}_{2} \mathrm{X}_{3}-0.0554 \mathrm{X}_{1} \mathrm{X}_{2} \mathrm{X}_{4}+0.0838 \mathrm{X}_{1} \mathrm{X}_{3} \mathrm{X}_{4}+0.0354 \mathrm{X}_{2} \mathrm{X}_{3} \mathrm{X}_{4} \\
& \\
& \mathrm{Ra}=0.5222-0.0271 \mathrm{X}_{1}+0.0419 \mathrm{X}_{2}+0.0866 \mathrm{X}_{3}-0.1346 \mathrm{X}_{4}+0.0013 \mathrm{X}_{1} \mathrm{X}_{2} \\
& +0.009 \mathrm{X}_{1} \mathrm{X}_{3}-0.009 \mathrm{X}_{1} \mathrm{X}_{4}+0.0235 \mathrm{X}_{2} \mathrm{X}_{3}+0.0042 \mathrm{X}_{2} \mathrm{X}_{4}-0.0255 \mathrm{X}_{3} \mathrm{X}_{4} \\
& +0.0681 \mathrm{X}_{1} \mathrm{X}_{2} \mathrm{X}_{3}-0.0519 \mathrm{X}_{1} \mathrm{X}_{2} \mathrm{X}_{4}-0.0081 \mathrm{X}_{1} \mathrm{X}_{3} \mathrm{X}_{4}+0.0041 \mathrm{X}_{2} \mathrm{X}_{3} \mathrm{X}_{4}
\end{aligned}
$$

\section{Main and Interaction Effects of Parameters on Surface Roughness}

From the ANOVA results of both cases, the main effects of parameters are not significant in the case of $\mathrm{AAB}$ and are highly significant in $\mathrm{PB}$. The main effects of parameters in the PB case are illustrated in Figure 4. It can be noted from the figure that 
increases in values of force, speed and number of passes reduce the surface roughness values, whereas the reverse trend was observed with burnishing feed. The observations are similar to the results of the work [2]. As a force, speed and number of passes levels increases, within the range selected in current work, the deformation action of the peaks will be effective, to fill the adjacent valleys and this action leads to decrease the roughness. Increase in the level of feed results in excess strain hardening due to repeated deformation of the peaks causing deteriorate in roughness.

In the presence of abrasive paste between roller and workpiece, as observed from Figure 5, the effect of a number of passes found to be significantly followed by force. Increase in feed and speed adversely affected surface roughness. In all the cases presence of abrasive particles causes strain hardening, restricting plastic deformation to continue and resulted in a decrease of roughness values at the surface. When the number of passes and force increases at lesser levels, plastic deformation decreases due to recovery. It is evident from the figure that the reduction in roughness is more in $A A B$ than PB. The sharp edges of the abrasive particles acting in between the tool and workpiece reduce the length of the peaks further, which bring down the surface roughness level.

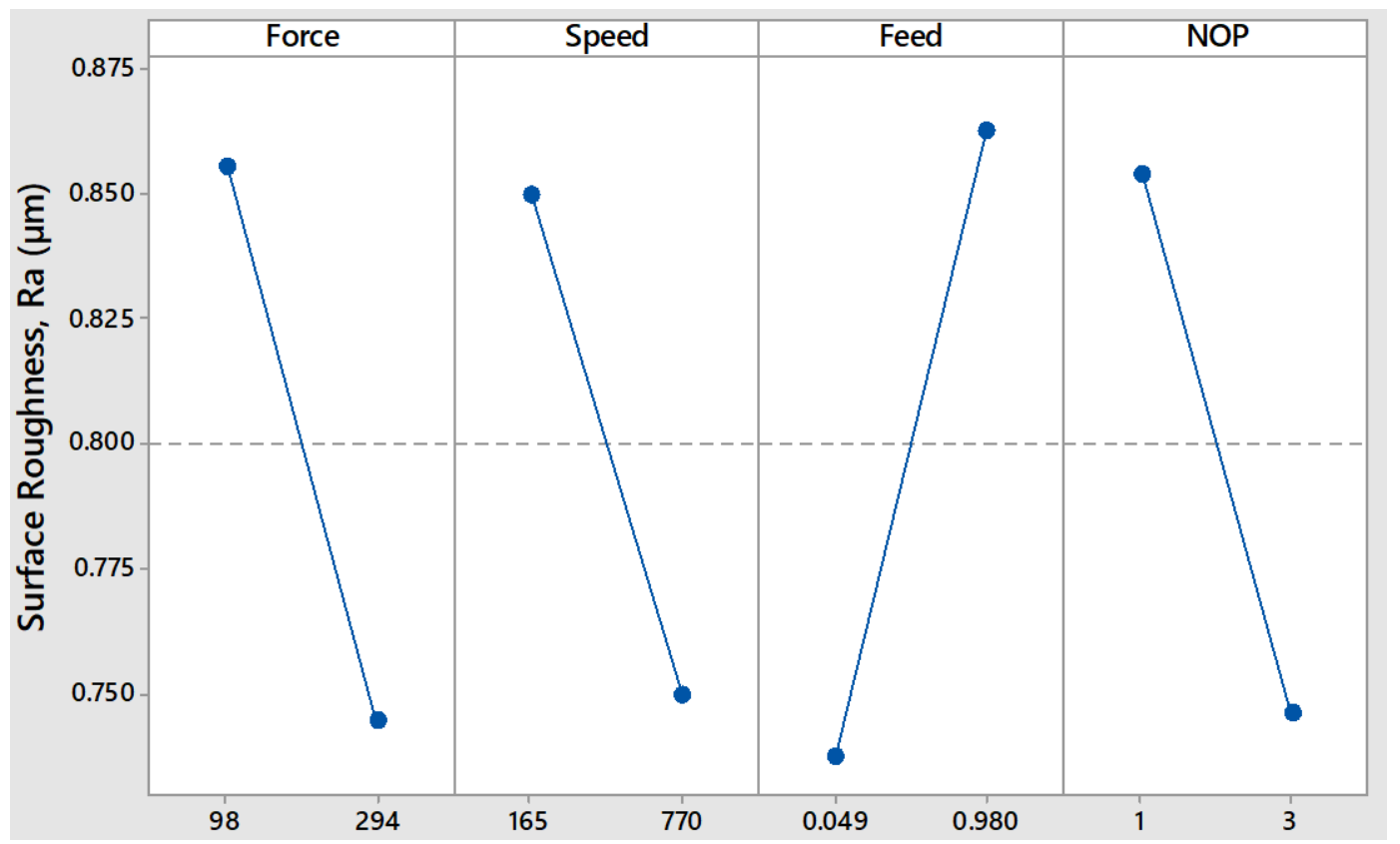

Figure 4. Main effects of parameters in PB. 


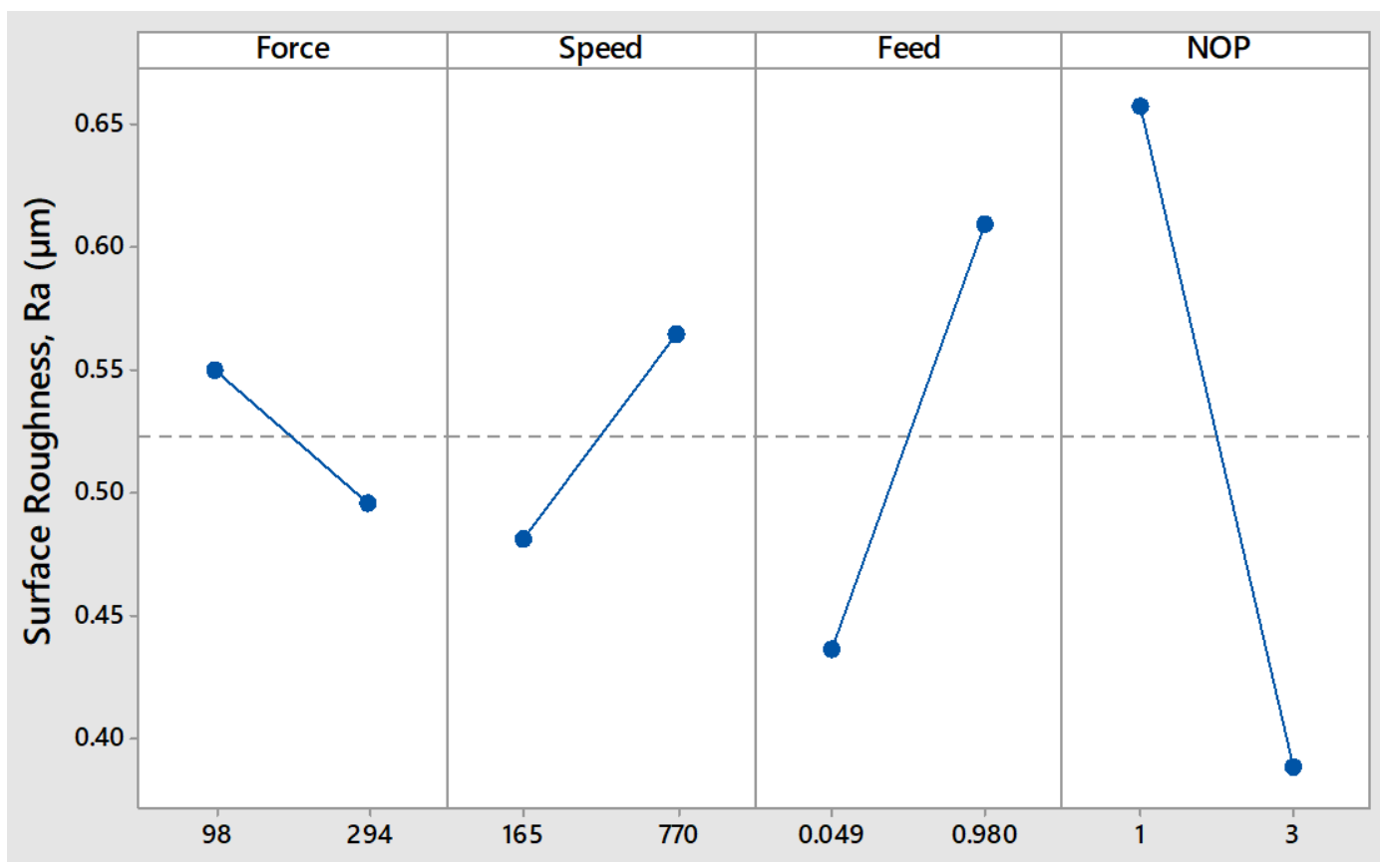

Figure 5. Main effects of parameters in AAB.

Figure 6 shows the interaction effects of force and feed on speed. It is observed that for all value of forces, the surface roughness increases with an increase in speed in the presence of abrasive particles. At lower speed the abrasives are forcing the peaks to fill the valleys causing plastic deformation, but when speed increases due to the combined action of high speed and abrasives roughness start deteriorates. The main cause may be the strain hardening recovery at the surface. Feed was found to have a similar effect on roughness, and hence low speed gives better surface roughness values at all values of force and feed.

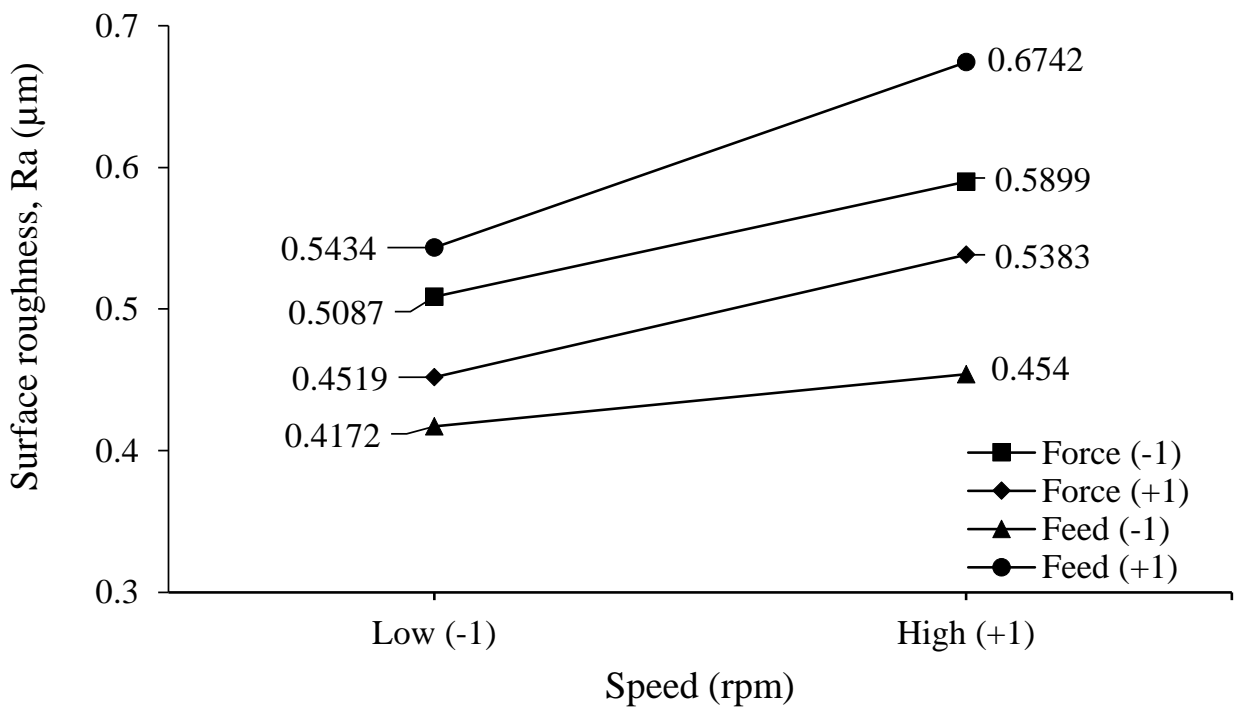

Figure 6. Interaction between speed, force and feed in AAB. 
Figure 7 depicts the effect of force and feed, force and number of passes on roughness. The figure shows that as force varies low to high at any value of feed the roughness at the surface decreases, indicating the higher value of forces are beneficial to get enough amount of plastic deformation. A similar effect was also observed for the number of passes.

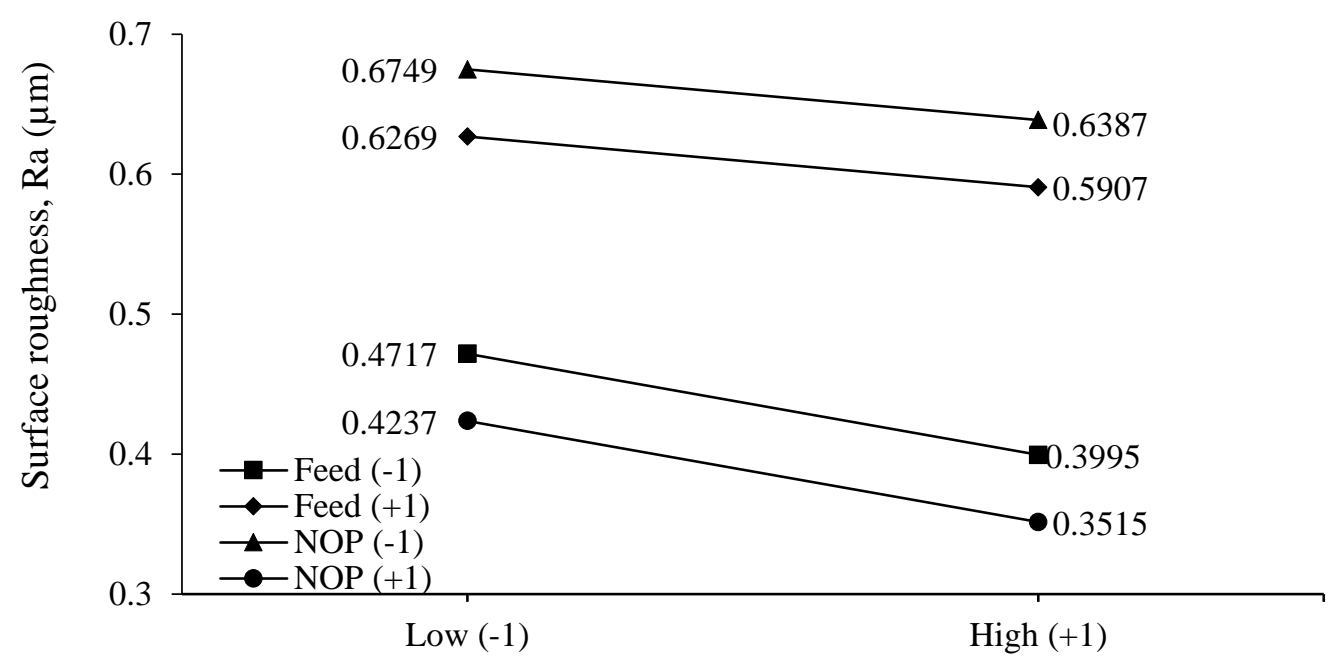

Force (kgf)

Figure 7. Interaction of force, feed and number of passes in $\mathrm{AAB}$.

The higher number of passes results in better surface roughness for all value of speed as shown in Figure 8. When speed is at a higher level, and the number of passes is low the repeated movement of roller over the surface to cause deformation will be less to increase the surface roughness value at the surface, and it is applicable for the lowspeed level. The same explanation holds good for both the level of feed. Overall, the interaction effects of parameters were found to be insignificant in case of AAB case.

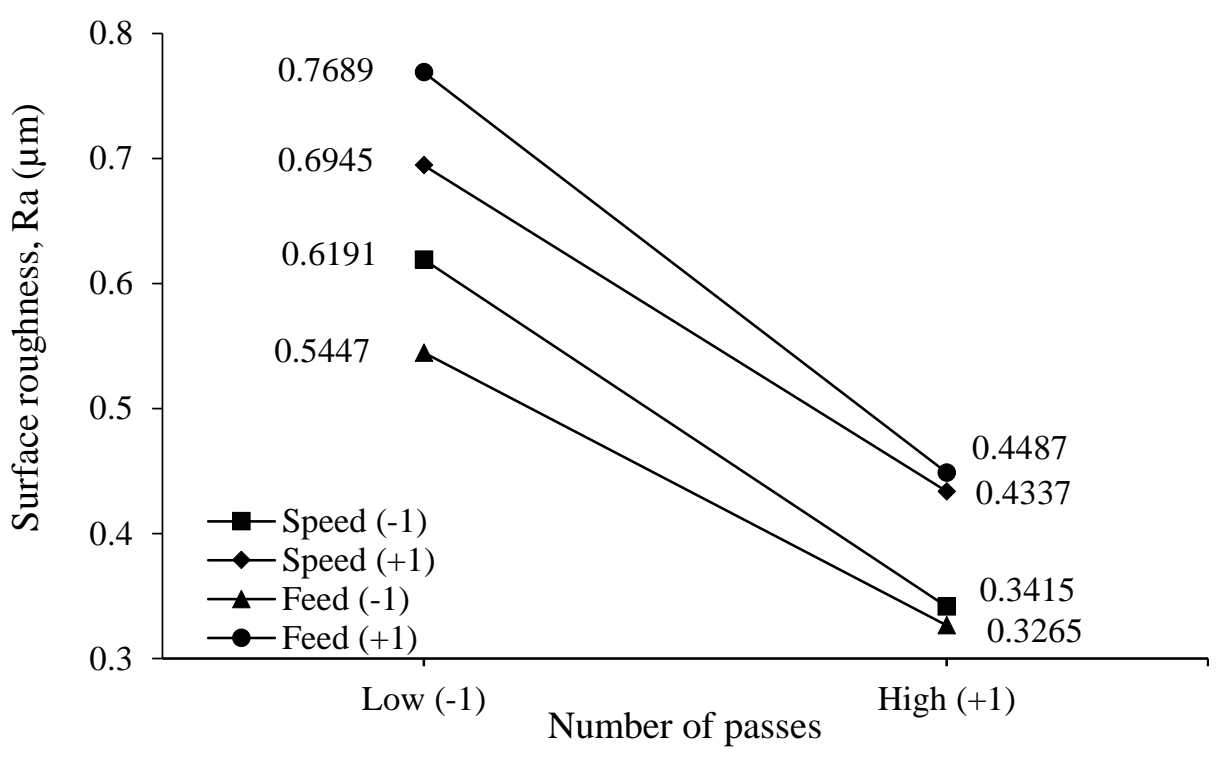

Figure 8. Interaction between number of passes, speed and feed in AAB. 
For PB case, low speed and high-speed levels at all value of a number of passes, surface roughness reduces but the reduction in the roughness value for the same case is lesser than AAB case. This is attributed to the presence of abrasive particles which acts along with roller to cause more plastic deformation. A similar trend was observed in the feed parameter as shown in Figure 9. The high number of passes and low feed reduces the surface roughness to a greater level when force increases. But as depicted in Figure 10, number of passes and high feed levels at higher force causes insufficient plastic deformation and excess strain hardening that results in less improvement in roughness.

The speed against force in Figure 11 indicates that roughness reaches the low level for all value of force when speed increases from low to high level. As speed increases, with force, sufficient strain hardening takes place to decrease roughness. Similar results are obtained in the case of feed also.

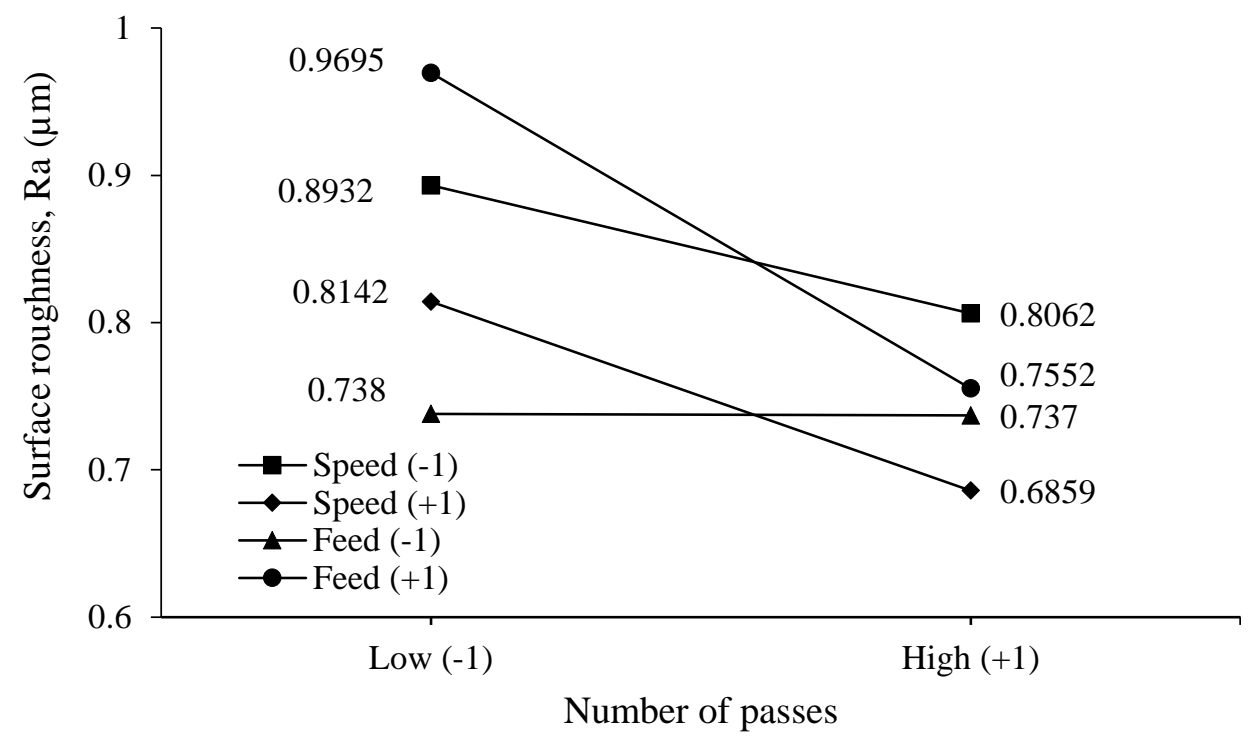

Figure 9. Interaction between number of passes, speed and feed in PB.

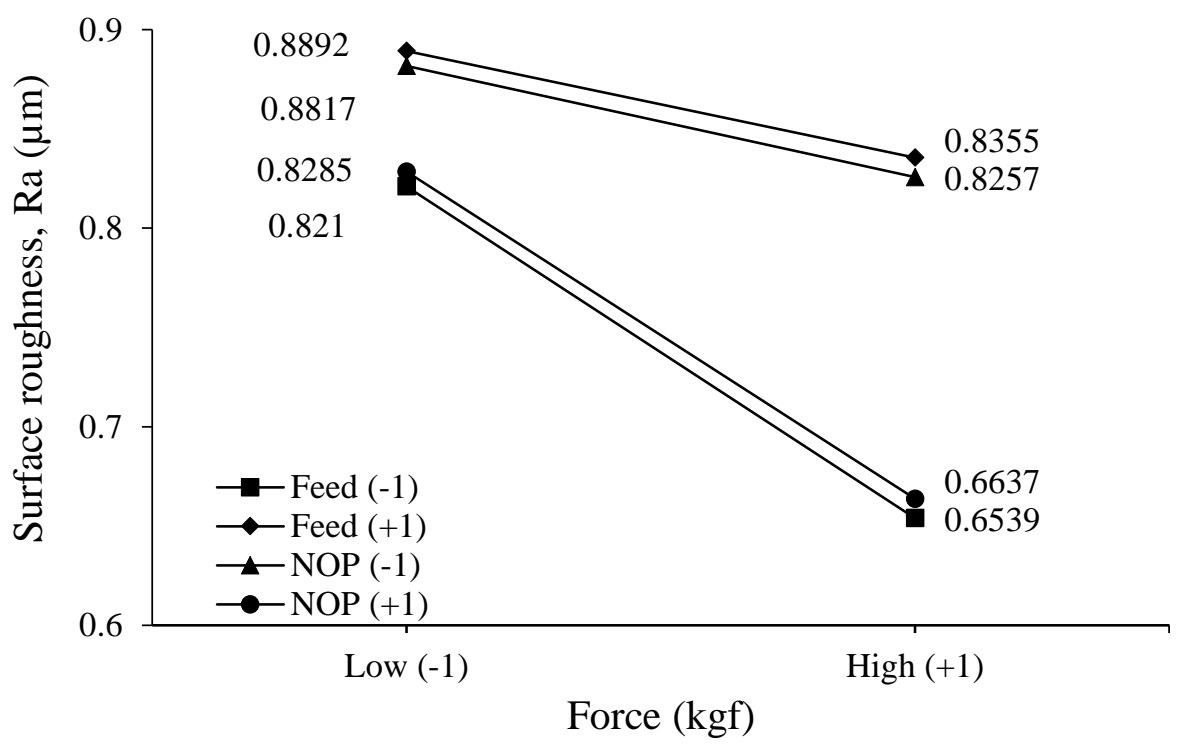

Figure 10. Interaction of force, feed and number of passes in PB. 


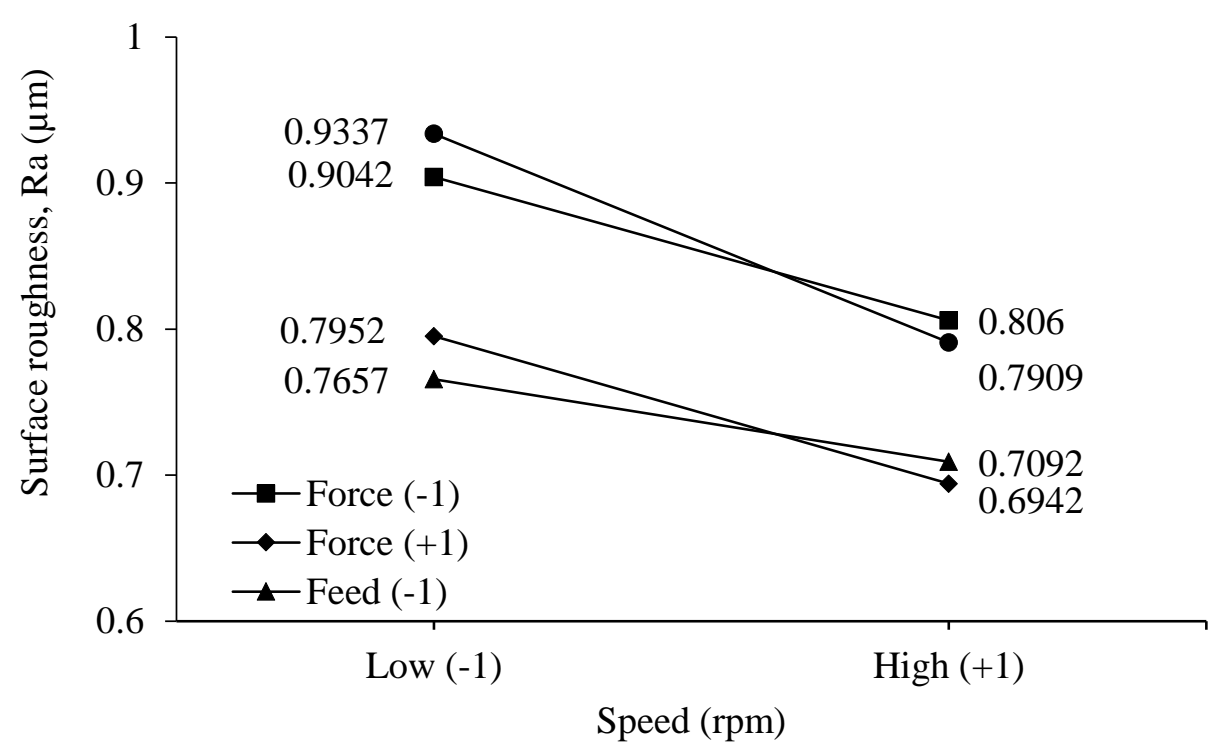

Figure 11. Interaction of speed, force and feed in PB.

\section{Analysis of Variance}

The ANOVA results are tabulated in Table 4 and Table 5 where values are lower than the confidence level of 0.05 . Hence all the factors are statistically significant, and it can be concluded that the model is adequate. The percentage of the effect of individual parameters on the surface roughness is mentioned in the tables. It is evident from the values that the three-level interactions have a higher effect, i.e. $50.92 \%$ on surface roughness followed by individual-level parameter effect $(35 \%)$ and two-level interaction factors $(14 \%)$. The feed as a single parameter is affecting surface roughness up to $11 \%$ followed by force $(8.65 \%)$, number of passes $(8.22 \%)$ and speed $(7 \%)$.

Results in Table 5 depict that the P-values are higher than confidence level indicating none of the parameters is statistically significant and only the paste used in the current work is contributing to the surface roughness. However, the percentage of contribution of the individual and interaction levels of parameters can be drawn from the ANOVA table. The parameters individually are having $61 \%$ effect on surface roughness followed by $16 \%$ effect of three-level interaction factors and very less effect of two-level interactions, i.e. $3 \%$. In individual level, the parameters number of passes and feed are found to be significant with $39 \%$ and $16 \%$ effect on surface roughness. Interestingly the force was only $1 \%$ while the speed contributes $3.83 \%$ in surface roughness. As noticed from the table the error is $19 \%$ which is probably because of the use of abrasive particles. The abrasive particles which are small in size and having random orientation applied to the pre-machined surface before carrying out the burnishing operation manually as a thin layer. The suspended abrasive particles were randomly spread across the specimen length. 
Table 4. Analysis of variance for PB $(\alpha=0.05)$.

\begin{tabular}{ccccccc}
\hline Source & DF & Adj. SS & Adj. MS & F-Value & P-Value & $\begin{array}{c}\text { \% effect on } \\
\text { Ra }\end{array}$ \\
\hline Model & 14 & 0.563211 & 0.040229 & 2574.81 & 0.005 & 99.999822 \\
Linear & 4 & 0.197139 & 0.049285 & 31542.20 & 0.004 & 35.002628 \\
Force & 1 & 0.048731 & 0.048731 & 31187.56 & 0.004 & 8.652337 \\
Speed & 1 & 0.039701 & 0.039701 & 25408.36 & 0.004 & 7.049033 \\
Feed & 1 & 0.062375 & 0.062375 & 39920.04 & 0.003 & 11.074871 \\
NOP & 1 & 0.046333 & 0.046333 & 29652.84 & 0.004 & 8.2265648 \\
2-Way Interactions & 6 & 0.079276 & 0.013213 & 8456.09 & 0.008 & 14.075694 \\
Force*Speed & 1 & 0.000008 & 0.000008 & 4.84 & 0.272 & 0.0014204 \\
Force*Feed & 1 & 0.012826 & 0.012826 & 8208.36 & 0.007 & 2.2772952 \\
Force*NOP & 1 & 0.011827 & 0.011827 & 7569.00 & 0.007 & 2.0999197 \\
Speed*Feed & 1 & 0.007439 & 0.007439 & 4761.00 & 0.009 & 1.320817 \\
Speed*NOP & 1 & 0.001702 & 0.001702 & 1089.00 & 0.019 & 0.3021953 \\
Feed*NOP & 1 & 0.045476 & 0.045476 & 29104.36 & 0.004 & 8.0744018 \\
3-Way Interactions & 4 & 0.286797 & 0.071699 & 45887.48 & 0.004 & 50.921678 \\
Force*Speed*Feed & 1 & 0.105138 & 0.105138 & 67288.36 & 0.002 & 18.667571 \\
Force*Speed*NOP & 1 & 0.049173 & 0.049173 & 31470.76 & 0.004 & 8.7308154 \\
Force*Feed*NOP & 1 & 0.112393 & 0.112393 & 71931.24 & 0.002 & 19.955718 \\
Speed*Feed*NOP & 1 & 0.020093 & 0.020093 & 12859.56 & 0.006 & 3.5675731 \\
Error & 1 & 0.000002 & 0.000002 & & & 0.0003551 \\
Total & 15 & 0.563213 & & & & \\
Model Summary: & S & \multicolumn{7}{c}{ R-sq } & R-sq(adj) & R-sq(pred) \\
\hline
\end{tabular}

Table 5. Analysis of variance for AAB $(\alpha=0.05)$.

\begin{tabular}{ccccccc}
\hline Source & DF & Adj. SS & Adj. MS & F-Value & $\begin{array}{c}\text { P- } \\
\text { Value }\end{array}$ & $\begin{array}{c}\text { \% effect on } \\
\text { Ra }\end{array}$ \\
\hline Model & 14 & 0.590660 & 0.042190 & 0.30 & 0.911 & 80.770151 \\
Linear & 4 & 0.449873 & 0.112468 & 0.80 & 0.674 & 61.51815 \\
Force & 1 & 0.011772 & 0.011772 & 0.08 & 0.821 & 1.6097691 \\
Speed & 1 & 0.028056 & 0.028056 & 0.20 & 0.733 & 3.8365343 \\
Feed & 1 & 0.120062 & 0.120062 & 0.85 & 0.525 & 16.417949 \\
NOP & 1 & 0.289982 & 0.289982 & 2.06 & 0.387 & 39.65376 \\
2-Way Interactions & 6 & 0.022146 & 0.003691 & 0.03 & 0.999 & 3.0283679 \\
Force*Speed & 1 & 0.000025 & 0.000025 & 0.00 & 0.992 & 0.0034186 \\
Force*Feed & 1 & 0.001296 & 0.001296 & 0.01 & 0.939 & 0.1772223 \\
Force*NOP & 1 & 0.001296 & 0.001296 & 0.01 & 0.939 & 0.1772223 \\
Speed*Feed & 1 & 0.008836 & 0.008836 & 0.06 & 0.844 & 1.208284 \\
Speed*NOP & 1 & 0.000289 & 0.000289 & 0.00 & 0.971 & 0.0395195 \\
Feed*NOP & 1 & 0.010404 & 0.010404 & 0.07 & 0.831 & 1.4227011 \\
3-Way Interactions & 4 & 0.118641 & 0.029660 & 0.21 & 0.905 & 16.223634 \\
Force*Speed*Feed & 1 & 0.074256 & 0.074256 & 0.53 & 0.600 & 10.154181 \\
Force*Speed*NOP & 1 & 0.043056 & 0.043056 & 0.31 & 0.678 & 5.8877182 \\
Force*Feed*NOP & 1 & 0.001056 & 0.001056 & 0.01 & 0.945 & 0.1444033 \\
Speed*Feed*NOP & 1 & 0.000272 & 0.000272 & 0.00 & 0.972 & 0.0371948 \\
Error & 1 & 0.140625 & 0.140625 & & & 19.229849 \\
Total & 15 & 0.731285 & & & & \\
Model Summary: & S & \multicolumn{2}{c}{ R-sq } & & R-sq(adj) & R-sq(pred) \\
\hline
\end{tabular}


During operation the abrasive particles with random orientation occupied the space in between the tool and workpiece, the peaks present on the workpiece may undergo super squeezing due to the combined action of the sharp cutting edges of the abrasives and tool pressure. This helps in reducing the heights of the irregularities to a much lower level causing a reduction in surface roughness. Thus, the presence of abrasives may become another parameter to enhance the surface finish in the burnishing operation. Due to the dearth of literature in burnishing and based on the results obtained in the current work, the use of the abrasive particles in burnishing can reduce the surface roughness by $15 \%$ in $\mathrm{AAB}$ process.

The comparison of surface roughness calculated from the mathematical models of Eq. (3), (4) and theoretical (from experimental) for both cases are given in Table 6 along with the percentage of error for reference.

Table 6. Comparison of theoretical and experimental Ra with percentage of error.

\begin{tabular}{ccccccc}
\hline \multirow{2}{*}{ Run } & \multicolumn{2}{c}{ Theoretical } & \multicolumn{2}{c}{ Experimental } & \multicolumn{2}{c}{ \% error } \\
\cline { 2 - 7 } & PB & AAB & PB & AAB & PB & AAB \\
\hline 1 & 1.3568 & 0.8287 & 1.285 & 0.928 & -5.59 & 10.70 \\
2 & 0.597 & 0.5413 & 0.667 & 0.453 & 10.49 & -19.49 \\
3 & 0.7551 & 0.6077 & 0.754 & 0.707 & -0.15 & 14.05 \\
4 & 0.9244 & 0.9517 & 0.925 & 1.040 & 0.06 & 8.49 \\
5 & 0.7529 & 0.3951 & 0.754 & 0.296 & 0.15 & -33.48 \\
6 & 0.8217 & 0.7003 & 0.821 & 0.612 & -0.09 & -14.43 \\
7 & 0.3308 & 0.1947 & 0.331 & 0.283 & 0.06 & 31.20 \\
8 & 0.8692 & 0.2209 & 0.868 & 0.320 & -0.14 & 30.97 \\
9 & 0.7974 & 0.4223 & 0.797 & 0.334 & -0.05 & -26.44 \\
10 & 0.8055 & 0.3277 & 0.806 & 0.416 & 0.06 & 21.23 \\
11 & 0.8457 & 0.5949 & 0.847 & 0.496 & 0.15 & -19.94 \\
12 & 0.6551 & 0.5347 & 0.654 & 0.634 & -0.17 & 15.66 \\
13 & 0.9953 & 0.4953 & 0.995 & 0.407 & -0.03 & -21.70 \\
14 & 0.763 & 0.5101 & 0.764 & 0.411 & 0.13 & -24.11 \\
15 & 0.7558 & 0.5183 & 0.757 & 0.419 & 0.16 & -23.70 \\
16 & 0.7735 & 0.5115 & 0.774 & 0.600 & 0.06 & 14.75 \\
\hline
\end{tabular}

\section{CONCLUSION}

The lowest surface roughness, $\mathrm{Ra}$, achieved in PB case is $0.331 \mu \mathrm{m}$ which is $75 \%$ better than turned workpiece surface roughness. The optimized parameters were at high force of $294 \mathrm{~N}$, high speed of $770 \mathrm{rpm}$, low feed of $0.049 \mathrm{~mm} / \mathrm{rev}$ and at three number of passes. The lowest surface roughness, Ra, achieved in AAB case is $0.283 \mu \mathrm{m}$ which is $90 \%$ better than turned workpiece and the optimized parameters to get the same were high force of $294 \mathrm{~N}$, high speed of $770 \mathrm{rpm}$, low feed of $0.049 \mathrm{~mm} / \mathrm{rev}$ and at three number of passes. Further $15 \%$ improvement can be achieved by using abrasive particles in $\mathrm{AAB}$ compared to $\mathrm{PB}$ indicating its positive role in the process.

\section{REFERENCES}

[1] Wick C, Veilleuy RF. Tool and Manufacturing Engineers Handbook Society of Manufacturing Engineers, 1985, p 30-47.

[2] Hassan AM, Al-Bsharat AS. Influence of burnishing process on surface roughness, hardness, and microstructure of some non-ferrous metals. Wear 1996; 
199(1): 1-8.

[3] Hassan AM, Maqableh AM. The effects of initial burnishing parameters on nonferrous components. Journal of Materials Processing Technology 2000; 102(1): 115-121.

[4] Hamadache H, Laouar L, Zeghib NE, Chaoui K. Characteristics of Rb40 steel superficial layer under ball and roller burnishing. Journal of Materials Processing Technology 2006; 180(1-3): 130-136.

[5] Rao DS, Hebbar HS, Komaraiah M, Kempaiah UN. Studies on the effect of ball burnishing parameters on surface hardness of HSLA dual-phase steels using factorial design. Transactions of the Indian Institute of Metals 2008; 61(2-3): 187-191.

[6] El-Tayeb NSM, Low KO, Brevern PV. On the surface and tribological characteristics of burnished cylindrical Al-6061. Tribology International 2009; 42(2): 320-326.

[7] Low KO, Wong KJ. Influence of ball burnishing on surface quality and tribological characteristics of polymers under dry sliding conditions. Tribology International 2011; 44(2): 144-153.

[8] El-Axir MH, Othman OM, Abodiena, AM. Improvements in out-of-roundness and microhardness of inner surfaces by internal ball burnishing process. Journal of materials processing technology 2008; 196(1-3): 120-128.

[9] Hassan AM, Momani AM. Further improvements in some properties of shot peened components using the burnishing process. International Journal of Machine Tools and Manufacture 2000; 40(12): 1775-1786.

[10] Hassan AM. The effects of ball-and roller-burnishing on the surface roughness and hardness of some non-ferrous metals. Journal of materials processing technology 1997; 72(3): 385-391.

[11] El-Khabeery MM, El-Axir MH. Experimental techniques for studying the effects of milling roller-burnishing parameters on surface integrity. International Journal of Machine Tools and Manufacture 2001; 41(12): 1705-1719.

[12] El-Tayeb NSM, Low KO, Brevern PV. Influence of roller burnishing contact width and burnishing orientation on surface quality and tribological behaviour of Aluminium 6061. Journal of materials processing technology 2007; 186(1-3): 272-278.

[13] Tekkaya AE, Kleiner M, Biermann D, Hiegemann L, Rausch S, Franzen V, Kersting PA. Friction analysis of thermally sprayed coatings finished by ball burnishing and grinding. Production Engineering 2013; 7(6): 601-610.

[14] Salahshoor M, Guo YB. Process mechanics in ball burnishing biomedical magnesium - calcium alloy. The International Journal of Advanced Manufacturing Technology 2013; 64(1-4): 133-144.

[15] Caudill J, Huang B, Arvin C, Schoop J, Meyer K, Jawahir IS. Enhancing the surface integrity of Ti-6Al-4V alloy through cryogenic burnishing. Procedia CIRP 2014; 13: 243-248.

[16] Saldaña-Robles A, Plascencia-Mora H, Aguilera-Gómez E, Saldaña-Robles A, Marquez-Herrera A, Diosdado-De la Peña JA. Influence of ball-burnishing on roughness, hardness and corrosion resistance of AISI 1045 steel. Surface and Coatings Technology 2018; 339: 191-198.

[17] Devaraya G, Shetty R, Srinivas S, Neelakanth V. Wear resistance enhancement of titanium alloy ( $\mathrm{Ti}-6 \mathrm{Al}-4 \mathrm{~V}$ ) by ball burnishing process. Journal of Materials Research and Technology 2016; 6(1):13-32. 
[18] Taha Z, Salaam HA, Tuan Ya TMYS, Phoon SY, Tan CF, Akiah MA. Vortex Tube Air Cooling: The Effect on Surface Roughness and Power Consumption in Dry Turning. International Journal of Automotive and Mechanical Engineering 2013; 8: 1477-1486.

[19] Saha A. Empirical modelling of machining parameters for turning operations using multi objective Taguchi method. International Journal of Automotive and Mechanical Engineering 2017; 14: 4448-4461. 